\title{
New species of Apenesia (Hymenoptera, Bethylidae) from the Parque Nacional da Serra do Divisor, Acre, Brazil
}

\author{
Celso Oliveira Azevedo \\ Michel Lemos Batista ${ }^{1}$
}

\begin{abstract}
Ten new species of Apenesia Westwood, 1874, from Brazil, Acre, are described and illustrated. They belong, respectively, to the following species-groups: nitida group, Apenesia lobata sp. nov., A. serrulata sp. nov. and $A$. subangulata sp. nov.; laevigata group, A. ocullata sp. nov. and A. rostrum sp. nov.; columbana group, A. apicilata $\mathbf{s p .}$ nov.; mexicana group, A. triapicalis sp. nov.; brasiliensis group, A. megaventris sp. nov., A. ventosa $\mathbf{s p .}$ nov. and $A$. triangula sp. nov. New geographical records and some morphological data on A. funebris Evans, 1963, A. nitida (Kieffer, 1910) and A. truncaticeps (Kieffer, 1910) are added.
\end{abstract}

Keywords. Acre; Apenesia; Bethylidae; Brazil; Hymenoptera.

This is our third paper regarding the knowledgement of Apenesia Westwood, 1874 in Brazil. CoRRÊA \& AzEVEDo (2001) recorded six species in a secondary Atlantic Forest site of the Reserva Biológica de Duas Bocas, Espírito Santo. Leal \& Azevedo (2001) found nine species in eight sites of the Atlantic Forest in Paraná State. In this contribution, we report 13 species collected in 12 sites of the Amazon Forest in the Parque Nacional da Serra do Divisor, Acre State, from which ten are herein described as new.

The material examined was provided by the Coleção de Entomologia of the Universidade Federal do Acre (UFAC), and the holotypes are deposited in the Universidade Federal do Espírito Santo (UFES).

The nomenclature in this study follows Evans (1963). Main measurements and indices used are as follow: length of forewing (LFW); length of head (LH); width of head (WH); width of frons (WF); height of eye (HE); ocello-ocular line (OOL); width of ocelar triangle (WOT); diameter of anterior ocellus (DAO); vertex-ocular line (VOL). The nomenclature of integument sculpture follows HARRIS (1979).

\section{nitida species-group}

\section{Apenesia nitida (Kieffer, 1910)}

This species was known from Peru, Bolivia and Brazil, Rio de Janeiro (Evans 1966) and now it is recorded for the first time from Acre. Variations: ventral ramus of paramere and ventral ramus of digitus wider, apex of dorsal ramus of paramere not so curved.

Material examined. 1 male, BRAZIL, Acre, Parque Nacional da Serra do Divisor, ponto norte 5, 16-17.XI.1996, Malaise trap, E. F. Morato col. (UFES).

Apenesia truncaticeps (Kieffer, 1910)

This species was known from Peru and Bolivia, and now it is recorded for the first time from Brazil. Variation: apical lobes of aedeagus more rounded apically.

Material examined. 2 males, BRAZIL, Acre, Parque Nacional da Serra do Divisor, ponto norte 1, 10-11.XI.1996, Malaise trap, E. F. Morato col. (UFAC, UFES).

\section{Apenesia lobata sp. nov.}

(Figs. 1, 11)

Description. Holotype, male: length $4.33 \mathrm{~mm}$, LFW $3.00 \mathrm{~mm}$.

Color. Head and mesosoma black, metasoma dark castaneous, mandibles, antennae and legs castaneous, distal flagellomeres darker, wings hyaline.

Head (Fig. 1). Mandibles with one apical tooth large, the others forming a cutting edge. Clypeus with a median lobe narrow, truncate and projected, without median carina. First four antennal segments in a ratio of 20:5:11:10; segment III 2.8 $\mathrm{x}$ as long as thick; segment XI $3.0 \mathrm{x}$ as long as thick, pubescence suberect, with some erect setae, as long as the segment thickness. Eyes glabrous, inner margins parallel. Frons polished,

1. Departamento de Biologia, Universidade Federal do Espírito Santo. Av. Marechal Campos 1468, Maruípe, 29040-090 Vitória - ES, Brazil. E-mail: cazevedo@npd.ufes.br and michelbatista@escelsa.com.br. 
with few punctures very sparse. WH $1.02 \times$ LH; WF 0.6 x WH; WF $1.25 \times$ HE; OOL $1.65 \times$ WOT; posterior ocellus distant from the crest vertex $2.15 \times$ DAO, frontal angle of triangle ocellar acute. Vertex convex, corners rounded. VOL $0,73 \times \mathrm{HE}$.

Mesosoma. Pronotal disc with a very weak anterior carina, lateral margins straight, with a shallow posterior transverse depression. Notauli narrow and complete, convergent posteriorly. Parapsidal furrows absent in the anterior third. Propodeal disc $1.03 \mathrm{x}$ as wide as long, with basal triangle long, median carina complete, but weak behind, posterior carina very weak, declivity coriaceous.

Metasoma. Polished and petiolate. Genitalia (Fig. 11): paramere with apex very wide, inner corner rounded, apical margin horizontal, with an irregular concavity near ventral margin; volsella with ventral ramus of digitus thin, $0.5 \mathrm{x}$ as long as paramere, with a small basal callus; basivolsella rounded below; aedeagus with a pair of rounded apical lobes.

Material examined. Holotype, male, BRAZIL, Acre, Parque Nacional da Serra do Divisor, ponto norte 3, 12-13.XI.1996, Malaise trap, E. F. Morato col. (UFES). Paratype: 1 male, BRAZIL, Acre, Parque Nacional da Serra do Divisor, ponto sul 4, 14-15.III.1997, Malaise trap, E. F. Morato col. (UFAC).

Variation. Apical margin of paramere slightly inclined downward internally and its concavity deeper.

Remarks. This species resembles A. nitida by the shape of the clypeus, but differs by the paramere not deeply divided. The genitalia resembles that of A. truncaticeps, but here the apical lobes of the aedeagus are wider.

Etymology. The name refers to the wide apical lobes of aedeagus.

\section{Apenesia serrulata sp. nov.}

(Figs. 2, 12)

Description. Holotype, male: length $5.13 \mathrm{~mm}$, LFW $3.08 \mathrm{~mm}$.

Color. Head and mesosoma black, metasoma dark castaneous, mandibles, antennae, palpi and legs light castaneous, wings hyaline.

Head (Fig. 2). Mandibles with one apical tooth large, the others forming a cutting edge. Clypeus with a median lobe narrow and truncate, with a weak median carina. First four antennal segments in a ratio of 22:8:11:11; segment III $2.8 \mathrm{x}$ as long as thick; segment XI $3.0 \mathrm{x}$ as long as thick, pubescence erect, $0.8 \mathrm{x}$ as long as the segment thickness. Eyes glabrous, inner margins slightly divergent below. Frons polished and brilliant, with few punctures very sparse. WH $0.98 \times \mathrm{LH}$; WF $0.62 \times \mathrm{WH}$; WF 1.24 x HE; OOL 1.55 x WOT; posterior ocellus distant from the crest vertex $2.5 \times \mathrm{DAO}$, frontal angle of triangle ocellar acute. Vertex slightly convex, corners rounded. VOL $0.71 \times \mathrm{HE}$.

Mesosoma. Pronotal disc with a weak anterior carina, lateral margins straight, with a shallow posterior transverse depression. Notauli narrow, incomplete anteriorly, convergent behind.
Parapsidal furrows absent in the anterior third. Propodeal disc $0.9 \mathrm{x}$ as long as wide, basal triangle long, with median carina incomplete behind, posterior carinae ill-defined, declivity coriaceous with transverse striae above.

Metasoma. Polished and petiolate. Genitalia (Fig. 12): paramere with apex wide, apical margin inclined, with a small concavity near ventral margin, rounded internally; volsella with ventral ramus of digitus thin, less than $0.5 \mathrm{x}$ as long as paramere, with a large basal callus; basivolsella rounded below; aedeagus with two pairs of apical lobes, the lateral pair wide, with apex somewhat truncate, lateral margin serrate, the median pair thin and slightly longer than lateral pair.

Material examined. Holotype, male, BRAZIL, Acre, Parque Nacional da Serra do Divisor, ponto sul 6, 18-19.III.1997, Malaise trap, E. F. Morato col. (UFES). Paratype: 1 male, BRAZIL, Acre, Parque Nacional da Serra do Divisor, ponto sul 6, 18-19.III.1997, Malaise trap, E. F. Morato col. (UFAC).

Variation. Propodeal disc with median carina complete.

Remarks. Paratype with head missing. This species has a peculiar serrate lateral margin of aedeagus, which differs from all the known species of the nitida species-group. The median lobe of the clypeus resembles A. nitida, but in A. serrulata $\mathbf{s p .}$ nov. it is narrowly truncate.

Etymology. The name refers to the serrate lateral margin of aedeagus.

\section{Apenesia subangulata sp. nov.}

(Figs. 3, 13)

Description. Holotype, male: length $5.23 \mathrm{~mm}$, LFW $3.7 \mathrm{~mm}$.

Color. Head and mesosoma black, pronotal disc spotted with castaneous, metasoma, antennae, mandibles and legs castaneous, flagellomeres darker, palpi light castaneous, wings hyaline.

Head (Fig. 3). Mandibles with one apical tooth large, the others forming a cutting edge. Clypeus with median lobe angulate, median carina complete. First four antennal segments in a ratio of 22:6:14:15; segment III $3.5 \mathrm{x}$ as long as thick, segment $\mathrm{XI} 4.3 \mathrm{x}$ as long as thick, pubescence suberect, $0.75 \mathrm{x}$ as long as the segment thickness. Eyes with some short setae. Frons polished, with few punctures very sparse. WH $1.03 \times \mathrm{LH}$; WF $0.55 \times$ WH; WF $1.08 \times$ HE; OOL $1.38 \times$ WOT; posterior ocellus distant from the crest vertex $1.9 \times \mathrm{DAO}$, frontal angle of triangle ocellar acute. Vertex convex, corners rounded, occipital carina visible in dorsal view. VOL $0.61 \mathrm{x} \mathrm{HE}$.

Mesosoma. Pronotal disc with anterior carina, lateral margins straight, with a shallow posterior transverse depression. Notauli narrow and complete, convergent posteriorly. Parapsidal furrows absent in the anterior third. Propodeal disc $1.0 \mathrm{x}$ as wide as long, basal triangle long, reaching the posterior carina, median and posterior carinae complete, declivity with strong transverse striae.

Metasoma. Polished and petiolate. Genitalia (Fig. 13): 
paramere fused to basiparamere, apical margin with a large concavity, $0.33 \mathrm{x}$ as deep as the length of parameres, dorsal ramus wide and somewhat rounded; volsella with ventral ramus of digitus wide, apex somewhat truncate, wider than the base, $0.33 \mathrm{x}$ as long as the paramere; basivolsella rounded below; aedeagus with two pairs of apical lobes, the dorsal pair longer, thin apically, the ventral pair with a pair of inner filament and with a pair of short and gibbous expansion; basal bars much dilated and produced below.

Material examined. Holotype, male, BRAZIL, Acre, Parque Nacional da Serra do Divisor, ponto norte 3, 12-13.XI.1996, Malaise trap, E. F. Morato col. (UFES). Paratypes: 3 males, BRAZIL, Acre, Parque Nacional da Serra do Divisor, ponto norte 3 and ponto sul 4, 12-13.XI.1996 and 14-15.III.1997, Malaise trap, E. F. Morato col. (UFAC, UFES).

Variation. Mesosoma castaneous.

Remarks. One paratype in bad conditions. This is the first species of the nitida species-group with the median lobe of clypeus subangulate. It has the paramere and basiparamere fused, a peculiar character founded only in A. fusilis Corrêa \& Azevedo, 2001.

Etymology. The name refers to the subangulate median lobe of clypeus.

\section{laegivata species-group}

\section{Apenesia ocullata sp. nov.}

(Figs. 4, 14)

Description. Holotype, male: length $3.38 \mathrm{~mm}$; LFW $2.1 \mathrm{~mm}$.

Color. Head and mesosoma black, metasoma dark castaneous, mandibles and flagellomeres castaneous, legs and palpi light castaneous, wings hyaline.

Head (Fig. 4). Mandibles with five teeth, becoming larger to lower margin. Clypeus strongly projected, median lobe angulate, with a median carina very high and angled in profile. First four antennal segments in a ratio of 15:5:14:13; segment III $3.1 \mathrm{x}$ as long as thick; segment XI $3.0 \mathrm{x}$ as long as thick, pubescence suberect, $0.5 \mathrm{x}$ as long as the segment thickness. Eyes with few short setae. Frons polished, with few conspicuous punctures. WH 0.99 x LH; WF 0.53 x WH; WF 0.97 x HE, OOL 1.36 x WOT; posterior ocellus distant from the crest vertex 1.0 x DAO, frontal angle of triangle ocellar acute. Vertex badly convex, corners rounded, occipital carina visible in dorsal view. VOL $0.41 \mathrm{x} \mathrm{HE}$.

Mesosoma. Pronotal disc without anterior carina, lateral margins straight. Notauli complete, convergent behind. Parapsidal furrows incomplete at the anterior third. Propodeal disc $1.0 \mathrm{x}$ as wide as long, wholly striate, basal triangle thin, median carina incomplete, posterior carina ill-defined, declivity striate.

Metasoma. Polished and petiolate. Petiole long, $0.5 \mathrm{x}$ as long as the gastral tergite I. Genitalia (Fig. 14): paramere with apical half curved inward and as wide as the base, inner corners rounded; volsella with ventral ramus of digitus small and rounded apically; basivolsella wide and rounded below; aedeagus with a pair of wide apical lobes, ventral margin with a serrate process.

Material examined. Holotype, male, BRAZIL, Acre, Parque Nacional da Serra do Divisor, ponto sul 6, 18-19.III.1997, Malaise trap, E. F. Morato col. (UFES).

Remarks. The large eyes, the head little developed behind them and the serrate ventral margin of the aedeagus are peculiar to this species.

Etymology. The name refers to the large eyes.

\section{Apenesia rostrum sp. nov.}

(Figs. 5, 15)

Description. Holotype, male: length $4.53 \mathrm{~mm}$; LFW $3.38 \mathrm{~mm}$.

Color. Head and mesosoma black, metasoma dark castaneous, mandibles, antennae and legs castaneous, distal flagellomeres darker, palpi light castaneous, wings subhyaline.

Head (Fig. 5). Mandibles with five teeth, becoming larger to lower margin. Clypeus with median lobe trapezoidal, with a wide median tooth directed downward, the median carina very high and angled in profile. First four antennal segments in a ratio of 23:6:23:20, segment III $4.2 \mathrm{x}$ as long as thick, segment XI $4.9 \mathrm{x}$ as long as thick, pubescence suberect, as long as the segment thickness. Frons polished, with few conspicuous punctures. Eyes with few short setae and weakly convergent below. WH 1.07 x LH; WF 0.55 x WH; WF 1.03 x HE, OOL 1.29 $\mathrm{x}$ WOT; posterior ocellus distant from the crest vertex $1.43 \mathrm{x}$ DAO, frontal angle of ocellar triangle acute. Vertex slightly convex, corners rounded, occipital carina visible in dorsal view. VOL $0.36 \times$ HE.

Mesosoma. Pronotal disc without anterior carina, lateral margin nearly straight. Notauli somewhat wide, incomplete both anterior and posteriorly, convergent behind. Parapsidal furrows incomplete anteriorly. Propodeal disc $1.08 \mathrm{x}$ as wide as long, basal triangle well-defined, median carina incomplete, without posterior carina, declivity polished.

Metasoma. Polished and petiolate. Petiole long, $0.5 \mathrm{x}$ as long as gastral tergite I. Genitalia (Fig. 15): paramere with apical half angled inward, inner corners dilated and rounded, outer corner angled, base slightly narrower than the apex; volsella with ventral ramus of digitus less than one third smaller than paramere; basivolsella with basal margin little concave below; aedeagus with a pair of apical lobes curved inward as a sharpened end, ventral margin with a series of grooves medially.

Material examined. Holotype, male, BRAZIL, Acre, Parque Nacional da Serra do Divisor, ponto norte 5, 14-15.XI.1996, Malaise trap, E. F. Morato col. (UFES).

Remarks. The series of grooves at the ventral margin and the sharpened and curved apical lobes of the aedeagus are peculiar to this species.

Etymology. The name rostrum is a noun in apposition. It refers to the apical lobes of aedeagus. 

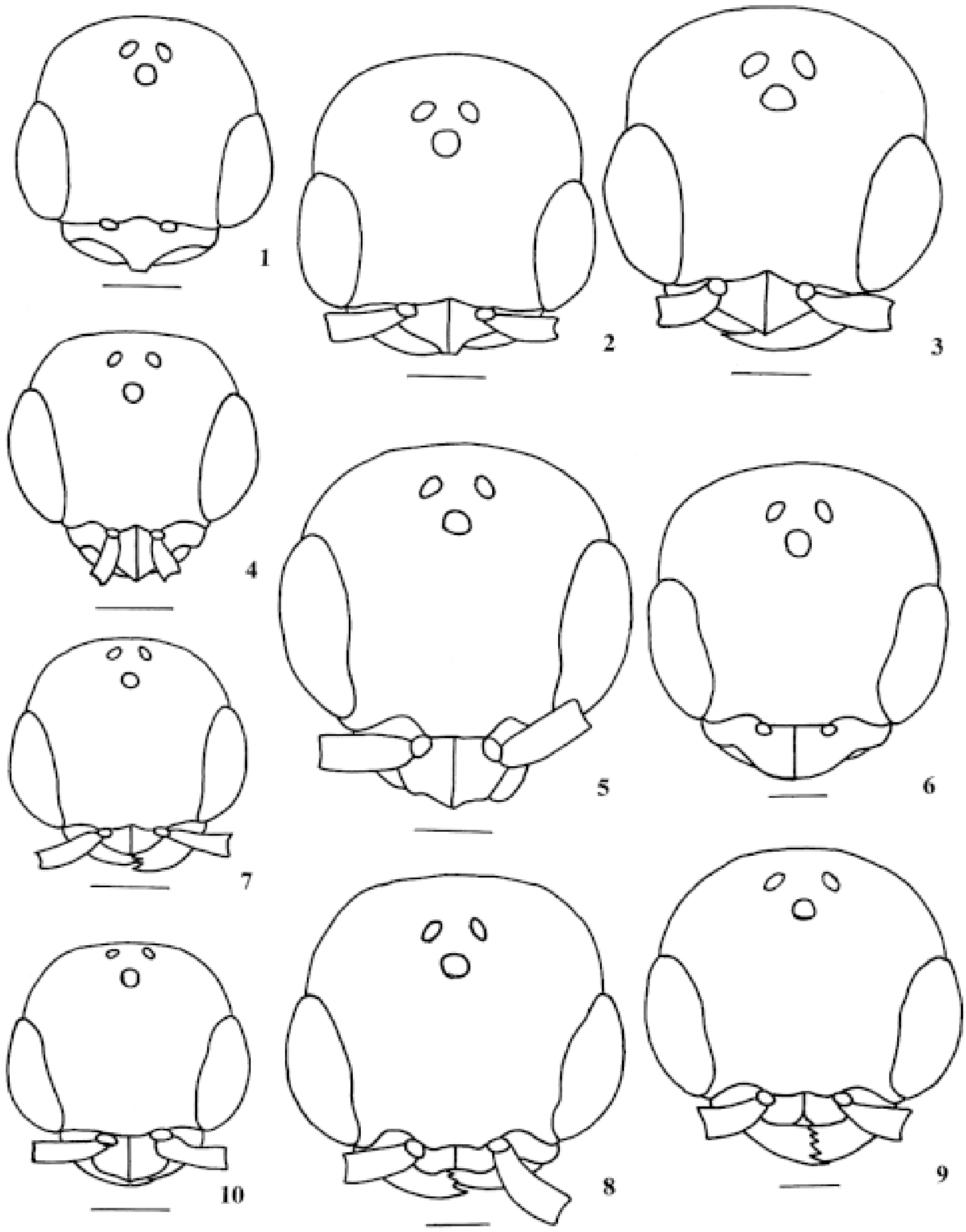

Figs. 1-10. Head (holotypes), dorsal view. 1, Apenesia lobata sp. nov.; 2, A. serrulata sp. nov.; 3, A. subangulata sp. nov.; 4, A. ocullata sp. nov.; 5, A. rostrum sp. nov.; 6, A. apicilata sp. nov.; 7, A. triapicalis sp. nov.; 8, A. megaventris sp. nov.; 9, A. ventosa sp. nov.; 10, A. triangula sp. nov. $($ scale bars $=250 \mu \mathrm{m})$. 


\section{columbana species-group}

\section{Apenesia funebris Evans, 1963}

This species was known from Brazil: Rio de Janeiro, Paraná and Santa Catarina (Leal \& Azevedo 2001) and now it is recorded for the first time from Acre. Variation: mandibles wholly castaneous.

Material examined. 1 male, BRAZIL, Acre, Parque Nacional da Serra do Divisor, ponto norte 6, 8-9.XI.1996, Malaise trap, E. F. Morato col. (UFES).

\section{Apenesia apicilata sp. nov.}

(Figs. 6, 16)

Description. Holotype, male: length $5.63 \mathrm{~mm}, \mathrm{LFW} 3.63 \mathrm{~mm}$.

Color. Head and mesosoma black, metasoma and antennae dark castaneous, mandibles, palpi and legs castaneous, wings hyaline.

Head (Fig. 6). Mandibles with five teeth, the two lower large, the upper larger than those below it. Clypeus with a strongly projected subrounded median lobe, with a median carina very high and angled in profile. First four antennal segments in a ratio of 15:4:15:14; segment III $2.5 \mathrm{x}$ as long as thick; segment $\mathrm{XI} 3.6 \mathrm{x}$ as long as thick, pubescence suberect, $0.5 \mathrm{x}$ as long as the segment thickness. Eyes with short setae. Frons polished, with few punctures somewhat conspicuous and very sparse. WH 0.93 x LH; WF 0.56 x WH; WF 1.09 x HE, OOL 1.5 x WOT; posterior ocellus distant from the crest vertex $2.0 \times$ DAO, frontal angle of ocellar triangle acute. Vertex convex, corners rounded. VOL $0.5 \times \mathrm{HE}$.

Mesosoma. Pronotal disc without anterior carina, lateral margins slightly concave; with a strong transverse depression. Notauli incomplete and very convergent behind. Parapsidal furrows incomplete anteriorly. Propodeal disc $1.22 \mathrm{x}$ as wide as long, basal triangle weakly defined, with two short longitudinal carinae, with median and posterior carinae complete, disc transversally waved, declivity reticulate above.

Metasoma. Weakly coriaceous anteriorly and polished behind in each segment; sessile. Genitalia (Fig. 16): paramere wide at apical fourth, apical margin badly concave; volsella with ventral ramus of digitus small and curved outward, cuspis nearly as high as aedeagus, apex rounded; basivolsella rounded below; aedeagus with a pair of apical lobes, apex dilated downward and rounded in lateral view, inner surface hairy.

Material examined. Holotype, male, BRAZIL, Acre, Parque Nacional da Serra do Divisor, ponto norte 9, 16-17.XI.1996, Malaise trap, E. F. Morato col. (UFES). Paratypes: 3 males, BRAZIL, Acre, Parque Nacional da Serra do Divisor, ponto norte 5 and 9, 16-21.XI.1996, Malaise trap, E. F. Morato col. (UFAC, UFES).

Variations. Legs darker, pubescence of the flagellomeres as long as the segments thickness, head longer.

Remarks. This species differs from the other species of the columbana species-group by having the lateral margin of the pronotal disc slightly concave and paramere wide only at the apical fourth.

Etymology. The name refers to the wide apex of paramere.

\section{mexicana species-group \\ Apenesia triapicalis sp. nov. \\ (Figs. 7, 17)}

Description. Holotype, male: length $3.58 \mathrm{~mm}, \mathrm{LWF} 2.4 \mathrm{~mm}$.

Color. Head and mesosoma black, metasoma dark castaneous, mandibles, antennae, palpi and legs castaneous, coxae and femora darker, wings hyaline.

Head (Fig. 7). Mandibles with four apical teeth, the two upper very small. Clypeus with median lobe rounded, with a small median tooth, with median carina complete. First four antennal segments in a ratio of 14:5:10:9, segment III $2.6 \mathrm{x}$ as long as thick, segment XI $2.7 \mathrm{x}$ as long as thick, pubescence dense and suberect, $0.5 \mathrm{x}$ as long as the segment thickness, with some setae which stand out the pubescence. Eyes glabrous and somewhat convergent. Frons coriaceous, with few punctures very sparse. WH 1.04 x LH; WF 0.53 x WH; WF 1.03 $\mathrm{x}$ HE; OOL $1.35 \mathrm{x}$ WOT; posterior ocellus distant from the crest vertex $1.0 \times \mathrm{DAO}$, frontal angle of ocellar triangle acute. Vertex convex, corners rounded, occipital carina visible in dorsal view. VOL $0.42 \times$ HE.

Mesosoma. Pronotal disc with median carina, lateral margins concave. Notauli complete, convergent behind. Parapsidal furrows absent in the anterior third. Propodeal disc $1.2 \mathrm{x}$ as wide as long, basal triangle ill-defined, short, disc coriaceous, median and posterior carinae complete, declivity coriaceous.

Metasoma. Weakly coriaceous and sessile. Genitalia (Fig. 17): paramere with surface concave internally, apical half $2.0 \mathrm{x}$ wider than the basal half, with corner rounded; volsella with ventral ramus of digitus wide, rounded, $0.5 \mathrm{x}$ as long as paramere; basivolsella rounded and wide below; aedeagus with three pairs of apical lobes, the dorsal pair with apex curved inward as a sharpened end, the median pair membranous and stout, the ventral pair rounded.

Material examined. Holotype, male, BRAZIL, Acre, Parque Nacional da Serra do Divisor, ponto norte 9, 20-21.XI.1996, Malaise trap, E. F. Morato col. (UFES).

Remarks. This species has a complex aedeagus with three pairs of apical lobes (Fig. 17).

Etymology. The name refers to the trilobate aedeagus.

\section{brasiliensis species-group}

\section{Apenesia megaventris sp. nov.} (Figs. 8, 18)

Description. Holotype, male: length $6.33 \mathrm{~mm}$, LFW $4.15 \mathrm{~mm}$. Color. Head and mesosoma black, metasoma dark 

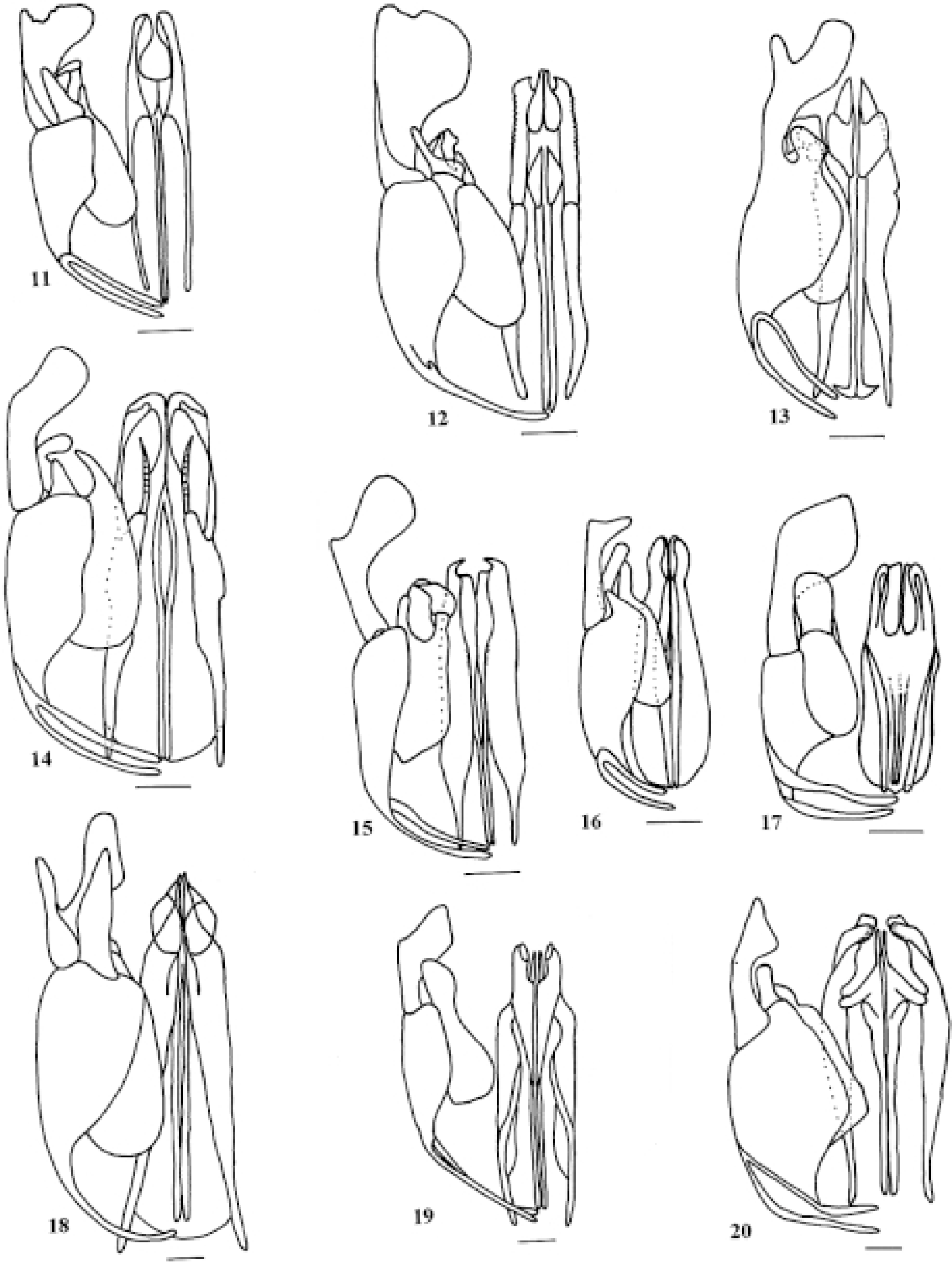

Figs. 11-20. Genitalia (holotypes), ventral view. 11, Apenesia lobata sp. nov.; 12, A. serrulata sp. nov.; 13, A. subangulata sp. nov.; 14, A. ocullata sp. nov.; 15, A. rostrum sp. nov.; 16, A. apicilata sp. nov.; 17, A. triapicalis sp. nov.; 18, A. megaventris sp. nov.; 19, A. ventosa sp. nov.; 20, A. triangula sp. nov. (scale bars $=100 \mu \mathrm{m}$ ). 
castaneous, mandibles, antennae, palpi and legs castaneous, wings subhyaline.

Head (Fig. 8). Mandibles with five teeth, the two lower large. Clypeus with median lobe broad and concave, median carina complete. First four antennal segments in a ratio of 36:8:16:16; segment III $2.1 \mathrm{x}$ as long as thick, pubescence dense, suberect, $0.4 \mathrm{x}$ as long as the segment thickness. Eyes with few sparse setae, slightly convergent below. Frons polished, with conspicuous punctures, separated by 1-3 x their diameters. WH 1.10 x LH; WF 0.55 x WH; WF 1.14 x HE; OOL 1.5 x WOT; posterior ocellus distant from the crest vertex $1.8 \times \mathrm{DAO}$, frontal angle of ocellar triangle acute. Vertex slightly convex, corners rounded, occipital carina visible in dorsal view. VOL $0.5 \times \mathrm{HE}$.

Mesosoma. Pronotal disc with a strong anterior carina, lateral margins straight. Notauli complete, dilated and convergent behind. Parapsidal furrows nearly complete. Propodeal disc $1.42 \mathrm{x}$ as wide as long, basal triangle large, striate, median carina incomplete, posterior complete, declivity striate.

Metasoma. Polished and with a short petiole. Genitalia (Fig. 18): paramere with two rami, the ventral ramus shorter and narrower, with base slightly wider than the rounded apex, dorsal ramus with apex dilated and subtriangular, base narrow; volsella with ventral ramus of digitus higher than the ventral ramus of paramere, with basal half evenly wide, narrowing to the apex; basivolsella wide and rounded below; aedeagus with two pairs of apical lobes, the median pair narrow, the ventral pair gibbous.

Material examined. Holotype, male, BRAZIL, Acre, Parque Nacional da Serra do Divisor, ponto norte 9, 20-21.XI.1996, Malaise trap, E. F. Morato col. (UFES). Paratypes: 2 males, BRAZIL, Acre, Parque Nacional da Serra do Divisor, ponto norte 6 and 8, 8-25.XI.1996, Malaise trap, E. F. Morato col. (UFAC, UFES).

Variation. Median lobe of clypeus subangulate.

Remarks. This species is very similar to A. lacereta Evans, 1969 by having the long ventral ramus of digitus and biramous paramere, but here the dorsal ramus of the paramere is subtriangular and the aedeagus is thin apically, while in $A$. lacerata the dorsal ramus of the paramere is quadrate and the aedeagus is wider apically. The variation in shape of the median lobe of clypeus is striking; this is one of the most remarkable character of the species in this genus.

Etymology. The name refers to the long ventral ramus of digitus.

\section{Apenesia ventosa sp. nov.}

(Figs. 9, 19)

Description. Holotype, male: length $5.1 \mathrm{~mm}$, LFW $3.6 \mathrm{~mm}$.

Color. Head and mesosoma black, metasoma, mandibles, antennae, palpi and legs castaneous, tibiae and tarsi lighter, wings subhyaline.

Head (Fig. 9). Mandibles with 5 teeth, the lower large, the upper slightly directed inward. Clypeus truncate and short, with median carina incomplete apically. First three antennal segments in a ratio of 24:6:13; segment III $2.2 \mathrm{x}$ as long as thick, with pubescence suberect and less than $0.5 \mathrm{x}$ the segment thickness. Eyes with a few short setae and weakly convergent. Frons polished, with punctures conspicuous. WH 1.12 x LH; WF 0.6 $\mathrm{x}$ WH; WF 1.21 x HE; OOL 1.61 x WOT; posterior ocellus distant from the crest vertex $1.92 \times \mathrm{DAO}$, frontal angle of ocellar triangle nearly right. Vertex slightly convex, corners rounded, occipital carina visible in dorsal view. VOL $0.53 \times \mathrm{HE}$.

Mesosoma. Pronotal disc with anterior carina, lateral margins straight. Notauli narrow and complete, dilated and slightly convergent behind. Parapsidal furrows incomplete anteriorly. Propodeal disc $1.46 \mathrm{x}$ as wide as long, basal triangle with longitudinal striae, with median and posterior carinae complete and strong, posterior area polished, declivity striate.

Metasoma. Polished and petiolate. Genitalia (Fig. 19): paramere with apex $3.0 \mathrm{x}$ as wide as the base and as wide as the height of paramere, upper and lower margins of apical half inclined, upper margin nearly straight, corners slightly angled; volsella with ventral ramus of digitus wide, rounded, and slightly longer than half length of paramere; basivolsella short and wide, with lower margin nearly straight, inner margins densely hairy above; aedeagus with two pairs of apical lobes, the outer pair stout with apex cut internally, the inner pair short, thin and straight.

Material examined. Holotype, male, BRAZIL, Acre, Parque Nacional da Serra do Divisor, ponto sul 9, 23-24.III.1997, Malaise trap, E. F. Morato col. (UFES).

Remarks: Holotype with antennae broken. This species runs to A. peruana (Kieffer, 1910) in the key of Evans (1963), but here the apical margin of the paramere is not concave and the aedeagus has a pair of thin inner apical lobes.

Etymology. The name refers to the shape of the outer apical lobes of aedeagus.

\section{Apenesia triangula sp. nov.}

(Figs. 10, 20)

Description. Holotype, male: length $4.09 \mathrm{~mm}$; LFW $2.3 \mathrm{~mm}$.

Color. Head and mesosoma black, metasoma dark castaneous, antennae, mandibles and legs castaneous, distal flagellomeres darker, palpi light castaneous, wings hyaline.

Head (Fig. 10). Mandibles with five teeth, becoming larger to lower margin. Clypeus with a strongly projected rounded median lobe, with a median carina very high and angled in profile. First four antennal segments in a ratio of 16:5:12:12, segment III $4.0 \mathrm{x}$ as long as thick, segment XI $4.0 \mathrm{x}$ as long as thick, pubescence erect and suberect, $0.85 \mathrm{x}$ as long as the segment thickness. WH 0.99 x LH; WF 0.55 x WH; WF 1.12 x HE, OOL $1.63 \times$ WOT; posterior ocellus distant from the crest vertex $1.0 \times \mathrm{DAO}$, frontal angle of ocellar triangle acute. Vertex slightly convex, corners rounded. VOL 0.5 x HE.

Mesosoma. Pronotal disc with a strong anterior carina, lateral margins concave. Notauli wide, complete, strongly convergent behind. Parapsidal furrows complete. Propodeal disc $0.95 \mathrm{x}$ as wide as long, median and posterior carina com- 
plete, with two discal carinae, declivity reticulate.

Metasoma. Polished and petiolate. Petiole very long, as long as the gastral tergite I. Genitalia (Fig. 20): paramere evenly arched inward, apex subtriangular, inner margins straight; volsella with ventral ramus of digitus one third of the length of paramere, apex rounded; basivolsella narrow in ventral view, inner margins straight and little hairy above; aedeagus wide, with a pair of wide apical lobes, with anterior apical membranous lobe and a subtriangular ventral expansion.

Material examined. Holotype, male, BRAZIL, Acre, Parque Nacional da Serra do Divisor, ponto sul 6, 23-24.III.1997, Malaise trap, E. F. Morato col. (UFES).

Remarks. This species is similar to A. parapolita Evans, 1958 and A. tarascana Evans, 1963 by having the clypeus projected, but it has a genitalia much different from all the known species of the brasiliensis species-group, with paramere relatively narrow and wide aedeagus.

Etymology. The name refers to the subtriangular paramere.
Acknowledgements. To the Laboratório de Genética (UFES) for the loan of the microscope used to illustrate the genitalia; to the curator E.F Morato (UFAC) for the loan of the material examined.

\section{REFERENCES}

Corrêa, M. S. \& C. O. Azevedo. 2001. Taxonomia de Apenesia (Hymenoptera, Bethylidae) na Reserva Biológica de Duas Bocas, Espírito Santo, Brazil. Iheringia, Série Zoologia, 90: 167-174.

Evans, H. E. 1963. A revision of the genus Apenesia in the Americas (Hymenoptera, Bethylidae). Bulletin of the Museum of Comparative Zoology 130(4):249-359.

Evans, H. E. 1966. Further studies on neotropical Pristocerinae (Hymenoptera, Bethylidae). Acta Hymenopterologica 2(3):99117.

Harris, R. A. 1979. A glossary of surface sculpturing. Occasional Papers in Entomology 28:1-31.

Leal, M. S. \& C. O. Azevedo. 2001. Taxonomy of Apenesia (Hymenoptera, Bethylidae) from Paraná, Brazil. Revista Brasileira de Zoologia 18(3): 673-679. 